\title{
Caracterização físico-quimica de farinhas não tradicionais e sua aplicação em barras
}

\section{de cereais}

\author{
Physicochemical characterization on non-traditional flours and their application in cereals bars \\ Caracterización fisicoquímica de harinas no tradicionales y su aplicación em barras de cereales
}

Recebido: 19/07/2021 | Revisado: 27/07/2021 | Aceito: 31/07/2021 | Publicado: 03/08/2021

\author{
Patrícia Chaves e Silva \\ ORCID: https://orcid.org/0000-0002-9987-3375 \\ Instituto Federal de Educação, Ciências e Tecnologia do Ceará, Brasil \\ E-mail: patrícia_csilva@yahoo.com.br \\ Maria Edlane de Almeida \\ ORCID: https://orcid.org/0000-0002-0709-1043 \\ Instituto Federal de Educação, Ciências e Tecnologia do Ceará, Brasil \\ E-mail: edlanealmeida.almeida@gmail.com \\ Maria Elenice Silva Lima \\ ORCID: https://orcid.org/0000-0002-9114-0804 \\ Instituto Federal de Educação, Ciências e Tecnologia do Ceará, Brasil \\ E-mail: elenice.silva.es@gmail.com \\ Renata Chastinet Braga \\ ORCID: https://orcid.org/0000-0001-6630-2835 \\ Instituto Federal de Educação, Ciências e Tecnologia do Ceará, Brasil \\ E-mail: rchastinet@ifce.edu.br \\ Anna Kelly Moreira da Silva \\ ORCID: https://orcid.org/0000-0002-6846-2549 \\ Instituto Federal de Educação, Ciências e Tecnologia do Piauí, Brasil \\ E-mail: annakellymoreira@yahoo.com.br \\ Daniele Maria Alves Teixeira Sá \\ ORCID: https://orcid.org/0000-0001-5477-7526 \\ Instituto Federal de Educação, Ciências e Tecnologia do Piauí, Brasil \\ E-mail: danielemaria@ifce.edu.br
}

\begin{abstract}
Resumo
O processamento do maracujá gera grande quantidade de resíduos, desperdiçando nutrientes que poderiam ser utilizados de forma alternativa para produção de farinhas não tradicionais. O objetivo do estudo foi elaborar farinha a partir do albedo de maracujá, caracterizá-la e comparar com farinhas comerciais, além de fabricar barras de cereais a partir de farinha de albedo, minimizando os resíduos gerados. As cascas foram doadas por uma indústria de polpa local, das quais foi extraído o albedo, que foi seco em estufa de circulação de ar e em seguida triturada para obtenção da farinha. Realizou-se análise centesimal e cor das farinhas (albedo e comerciais). Foram elaboradas quatro formulações de barras de cereais (Amostra BC 01, sem acréscimo da farinha do albedo do maracujá, Amostra BC 02, $3 \%$ da farinha, Amostra BC 03, 7\% da farinha e Amostra BC 04 11\% da farinha) e avaliado sua composição e valor calórico. Realizou-se análises microbiológicas e a testes de aceitação e intenção de compra. Observou-se que a farinha produzida apresentou um elevado teor de fibra bruta $(67,30 \%)$ e um baixa quantidade de lipídios e umidade $(0,40 \%$ e $7,52 \%)$, respectivamente, já as farinhas comerciais analisadas também apresentaram composição atendendo os padrões exigidos pela legislação, porém com maior quantidade de carboidrato. As barras de cereais atenderam aos padrões de aceitabilidade. Nos parâmetros sensoriais foi possível observar que a maioria dos provadores gostaram extremamente e gostaram muito das barras, afirmando que certamente comprariam o produto. Conclui-se que as farinhas de maracujá podem ser utilizadas como ingrediente alternativo no desenvolvimento e enriquecimento de alimentos, favorecendo a redução dos resíduos da agroindústria e trazendo potenciais benefícios para saúde.
\end{abstract}

Palavras-chave: Passiflora edulis; Farinha de maracujá; Albedo; Barra de cereais.

\begin{abstract}
Processing passion fruit generates a large amount of waste, wasting nutrients that could be used as an alternative for the production of non-traditional flours. The aim of the study was to prepare flour from passion fruit albedo, characterize it and compare it with commercial flours, in addition to manufacturing cereal bars from albedo flour, minimizing the waste generated. The husks were donated by a local pulp industry, from which the albedo was extracted, which was dried in an air-circulation oven and then crushed to obtain the flour. Proximate analysis and flour color (albedo and commercial) were performed. Four formulations of cereal bars were prepared (Sample BC 01, without addition of passion fruit albedo flour, Sample BC 02, 3\% of the flour, Sample BC 03, 7\% of the flour and
\end{abstract}


Sample BC $0411 \%$ of the flour) and evaluated its composition and caloric value. Microbiological analyzes and acceptance and purchase intent tests were performed. It was observed that the flour produced had a high content of crude fiber $(67.30 \%)$ and a low amount of lipids and moisture $(0.40 \%$ and $7.52 \%)$, respectively, while the commercial flours analyzed also presented composition meeting the standards required by law, but with a greater amount of carbohydrate. Cereal bars met acceptability standards. In the sensory parameters, it was possible to observe that most tasters really liked and liked the bars a lot, stating that they would certainly buy the product. It is concluded that passion fruit flours can be used as an alternative ingredient in the development and enrichment of foods, favoring the reduction of agroindustry residues and bringing potential health benefits.

Keywords: Passiflora edulis; Passion fruit flour; Albedo; Cereal bar.

\section{Resumen}

El procesamiento del maracuyá genera una gran cantidad de residuos, desperdiciando nutrientes que podrían utilizarse como alternativa para la producción de harinas no tradicionales. El objetivo del estudio fue preparar harina a partir de albedo de maracuyá, caracterizarla y compararla con harinas comerciales, además de fabricar barras de cereal a partir de harina de albedo, minimizando los residuos generados. Las cáscaras fueron donadas por una industria de pulpa local, de la cual se extraía el albedo, que se secaba en un horno de circulación de aire y luego se trituraba para obtener la harina. Se realizaron análisis próximos y color de la harina (albedo y comercial). Se prepararon cuatro formulaciones de barras de cereal (Muestra BC 01, sin adición de harina de albedo de maracuyá, Muestra BC 02, 3\% de la harina, Muestra BC 03, 7\% de la harina y Muestra BC $0411 \%$ de la harina) y evaluó su composición y valor calórico. Se realizaron análisis microbiológicos y pruebas de aceptación e intención de compra. Se observó que la harina producida tuvo un alto contenido de fibra cruda $(67,30 \%)$ y una baja cantidad de lípidos y humedad $(0,40 \%$ y $7,52 \%)$, respectivamente, mientras que las harinas comerciales analizadas también presentaron composición cumpliendo con los estándares exigidos por la ley. pero con una mayor cantidad de carbohidratos. Las barras de cereales cumplieron con los estándares de aceptabilidad. En los parámetros sensoriales, se pudo observar que a la mayoría de los catadores les gustaron mucho y les gustaron mucho las barras, afirmando que sin duda comprarían el producto. Se concluye que las harinas de maracuyá pueden utilizarse como ingrediente alternativo en el desarrollo y enriquecimiento de alimentos, favoreciendo la reducción de residuos agroindustriales y aportando potenciales beneficios para la salud.

Palabras clave: Passiflora edulis; Harina de maracuyá; Albedo; Barra de cereal.

\section{Introdução}

O setor de produção alimentícia gera diversos resíduos que são partes das matérias-primas não utilizadas ou descartadas durante o processamento, estes são em maioria mais ricos em nutrientes do que outras partes do alimento que estamos habituados a ingerir. As indústrias que trabalham com a utilização de frutas não são uma exceção quando se trata de desperdício, os resíduos gerados são principalmente cascas, caroços, sementes e bagaços, que possuem em possuem em sua composição vitaminas, minerais e fibras entre de outros (Damasceno et al., 2018; Padilha \& Basso, 2015).

Com a crescente ampliação das indústrias de alimentos, também ocorre um aumento na geração de resíduos, tendo em vista que cerca de um terço dos alimentos que são produzidos no Brasil são desperdiçados, gerando uma preocupação constante quanto ao seu destino. A busca por alternativas viáveis para utilização dos mesmos visa não só reduzir o descarte impróprio, mas também combater a insegurança alimentar e melhorar hábitos alimentares da população, o que tem levado ao desenvolvimentos de vários estudos sobre os uso de resíduos da agroindústria, dentre eles a produção de farinhas não convencionais provenientes de frutos como o abacaxi, baru, cajá, caju, maracujá, entre outros (Damasceno et al., 2018; Marcelino et al., 2018; Morais, 2018; Silva et al., 2018).

O maracujá amarelo ou maracujá azedo (Passiflora edulis f. Flavicarpa) produzido nas regiões tropicais e subtropicais é cultivado em larga escala em quase todo o Brasil e a quantidade de resíduos produzidos por toneladas de suco processado é bastante expressivo, sendo importante que um número cada vez maior de soluções sejam desenvolvidas para que o reaproveitamento dos mesmos seja possível (Damasceno et al., 2018, Silva et al., 2016; Corrêa et al., 2016).

A casca do maracujá, principal resíduo desta fruta, compõe $60 \%$ do seu peso, é composta pelo flavedo, rico em fibras insolúveis, e o albedo, rico em fibras solúveis, sendo a pectina a mais especial, que auxilia na redução de glicose no sangue, além de ser fonte de niacina (vitamina B3), ferro, cálcio e fósforo (Garcia, Milani \& Ries, 2019; Silva et al., 2016; 
Cazarin et al., 2014). A farinha produzida a partir da casca do maracujá é classificada como um alimento funcional, devido a sua composição vários estudos corroboram sua ação na saúde no controle do colesterol, glicemia e ação intestinal, desta forma essas farinhas vem sendo cada vez mais utilizadas por pacientes que buscam o controle e prevenção destas doenças uma vez que esses resultados já formaram comprovados em animais (Faveri et al., 2020; Maia et al., 2018; Silva et al., 2016; Lima, 2015).

Tendo em vista que a literatura vem comprovando grandes benefícios à saúde das farinhas não convencionais e não só para o enriquecimento e desenvolvimentos de produtos alimentícios, o presente trabalho teve como objetivo elaborar e caracterizar a farinha do albedo do maracujá, caracterizar farinhas de maracujá comerciais, a fim de compará-las e produzir e avaliar barras de cereais utilizando farinha de albedo de maracujá.

\section{Metodologia}

Trata-se de uma pesquisa analítica, na qual foi feita análise da relação entre variáveis que podem influenciar no resultado final do produto, de natureza quantitativa tendo em vista que foi feito um levantamento dados quantitativos através de experimentos com metodologias definidas, a fim de caracterizar os produtos em estudo e, laboratorial, pois foi realizada em ambiente com situações controladas (Pereira et al., 2018; Morais \& Fonseca, 2017).

\subsection{Obtenção da Farinha}

O processamento do albedo de maracujá para produção de farinha (Figura 1) foi realizado através de metodologia descrita por Ferreira et al. (2015) com adaptações. As demais farinhas foram adquiridas no mercado local de Limoeiro do Norte, Ceará - Brasil, no período de dezembro de 2019 e janeiro de 2020.

As cascas foram maceradas em água potável por $24 \mathrm{hs} \mathrm{com} \mathrm{trocas} \mathrm{a} \mathrm{cada} 4 \mathrm{hs}$, de acordo com metodologia descrita por Oliveira et al. (2002), adaptada, para reduzir ao máximo o amargo, em seguida foram submetidas a branqueamento e posteriormente foi feita a retirada do albedo (Figura 2A). Este foi levado a estufa com circulação de ar (marca HERAEUS INSTRUMENTALS, modelo UT-12) a temperatura de $65^{\circ} \mathrm{C} / 24 \mathrm{~h}$ para secagem (Figura 2B) e posteriormente triturada em moinho (marca FRITSCH, modelo Industriestrasse 8) para obtenção da farinha do albedo de maracujá (FAM) (Figura 3).

\subsection{Produção da Barra de Cereal}

\subsubsection{Pré-testes}

Foram realizados pré-testes até que obteve-se a formulação final. Decorrente dos estudos das formulações, foram elaboradas as formulações descritas na Tabela 1 e na Tabela 2, onde não resultaram em um produto com os padrões ideais de cor, odor, textura e sabor. 
Research, Society and Development, v. 10, n. 9, e60010918415, 2021

(CC BY 4.0) | ISSN 2525-3409 | DOI: http://dx.doi.org/10.33448/rsd-v10i9.18415

Figura 1 - Fluxograma de produção da Farinha do Albedo do Maracujá.

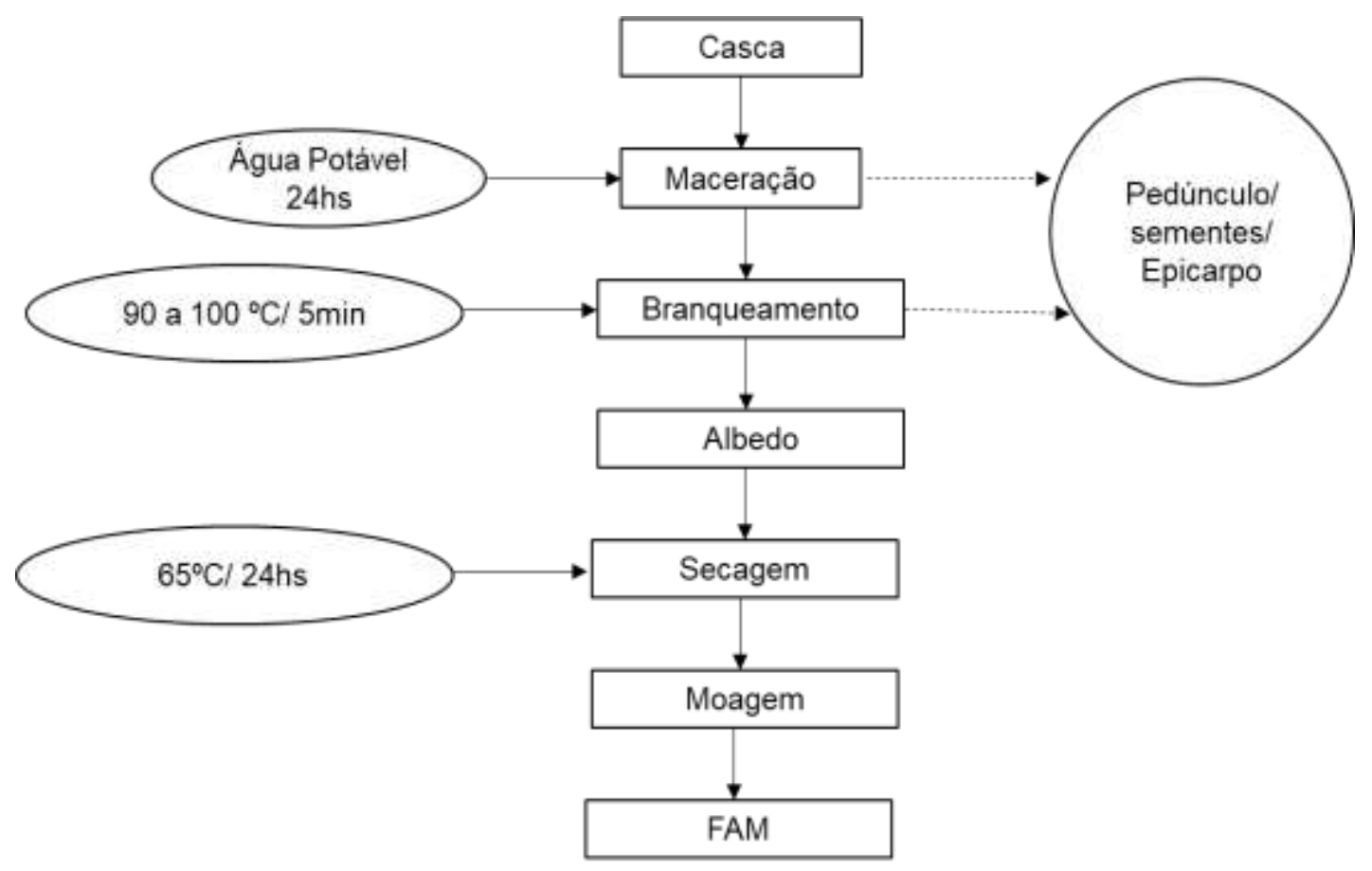

Fonte: Autores (2020).

Figura 2 - Extração do albedo e secagem do albedo.

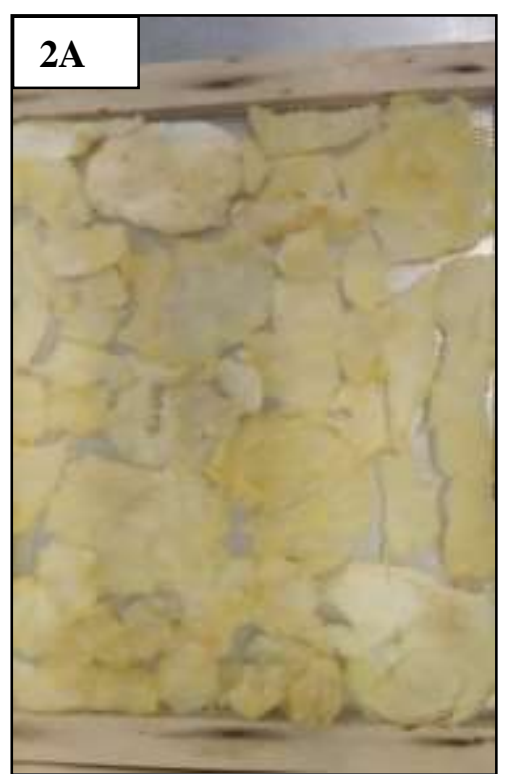

2A: albedo do maracujá.

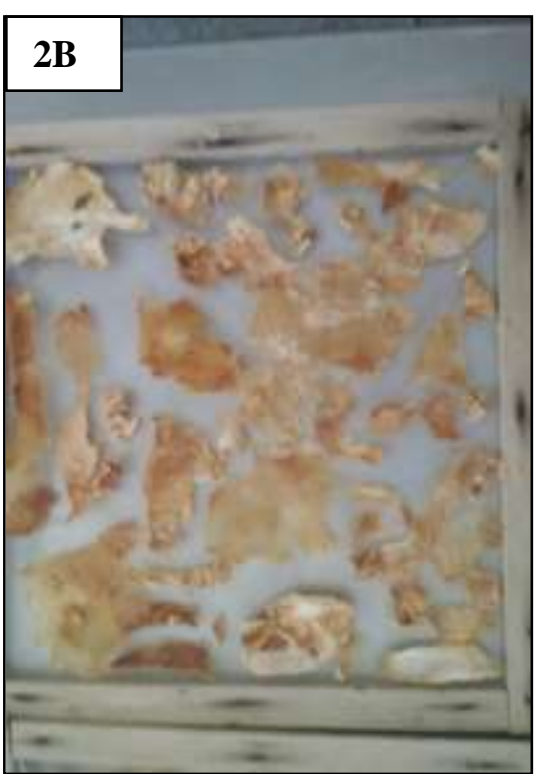

2B: Albedo seco.

Fonte: Autores (2020) 
Figura 3 - Farinha obtida do albedo do Maracujá.

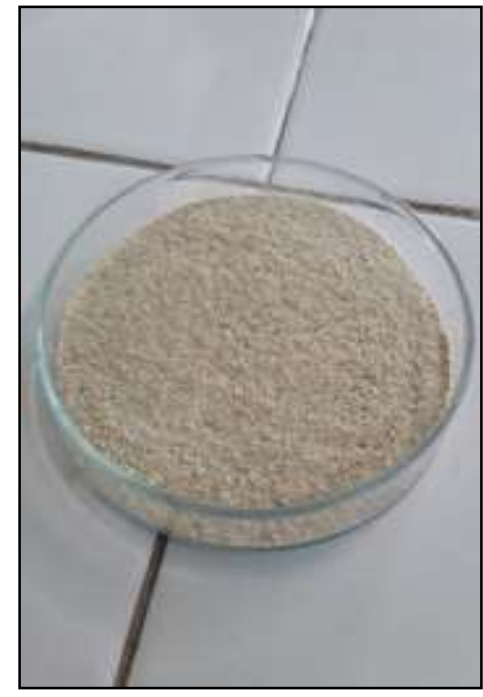

Fonte: Autores (2020)

Tabela 1 - Ingredientes das barras de cereais (Pré-teste 01).

\begin{tabular}{crrrr}
\hline Ingredientes & \multicolumn{3}{c}{ FORMULAÇÕES PRÉ-TESTE 01 \% } \\
& BC 01 & BC 02 & BC 03 & \multicolumn{1}{c}{ BC 04 } \\
\hline Aveia em flocos & 19 & 17,5 & 15,5 & 13,5 \\
Flocos de arroz & 12 & 10,5 & 8,5 & 6,5 \\
Castanha & 8 & 8 & 8 & 8 \\
Farinha de albedo & 0 & 3 & 7 & 11 \\
Coco ralado & 6 & 6 & 6 & 6 \\
Xarope de glicose & 27,5 & 27,5 & 27,5 & 27,5 \\
Açúcar mascavo & 10 & 10 & 10 & 10 \\
Mel de abelha & 9 & 9 & 9 & 9 \\
Gordura vegetal & 2 & 2 & 2 & 2 \\
Polpa de maracujá & 6,5 & 6,5 & 6,5 & 6,5 \\
\hline
\end{tabular}

BC 01 (barra de cereal com 0\% de albedo); BC 02 (barra de cereal com 3\% de albedo); BC 03 (barra de cereal com $7 \%$ de albedo); BC 04 (barra de cereal com $11 \%$ de albedo).

Fonte: Autores (2020).

Tabela 2 - Ingredientes das barras de cereais (Pré-teste 02).

\begin{tabular}{|c|c|c|c|c|}
\hline \multirow[t]{2}{*}{ Ingredientes } & \multicolumn{4}{|c|}{ FORMULAÇÕES PRÉ-TESTE $02 \%$} \\
\hline & ВC 01 & ВС 02 & BC 03 & ВC 04 \\
\hline Aveia em flocos & 20 & 18,5 & 16,5 & 14,5 \\
\hline Flocos de arroz & 12 & 10,5 & 8,5 & 6,5 \\
\hline Farinha de albedo & 0 & 3 & 7 & 11 \\
\hline Coco ralado & 7 & 7 & 7 & 7 \\
\hline Xarope de glicose & 27,5 & 27,5 & 27,5 & 27,5 \\
\hline Açúcar mascavo & 10 & 10 & 10 & 10 \\
\hline Mel de abelha & 10 & 10 & 10 & 10 \\
\hline Gordura vegetal & 3,5 & 3,5 & 3,5 & 3,5 \\
\hline Polpa de maracujá & 10 & 10 & 10 & 10 \\
\hline
\end{tabular}

BC 01 (barra de cereal com 0\% de albedo); BC 02 (barra de cereal com 3\% de albedo); BC 03 (barra de cereal com $7 \%$ de albedo); BC 04 (barra de cereal com $11 \%$ de albedo).

Fonte: Autores (2020). 
Para a produção da barra de cereais foram elaboradas quatro formulações com diferentes concentrações da farinha de albedo do maracujá. A formulação BC 01, não apresentou farinha de albedo de maracujá; a formulação BC 02 apresentou $3 \%$ dessa farinha, enquanto a BC 03 e BC 04 apresentaram 7\% e 11\%, respectivamente avaliando assim seu poder nutricional.

As barras de cereais foram elaboradas contendo uma fase líquida (xarope de aglutinação 58\%) e uma fase sólida (ingredientes secos $42 \%$ ). Na fase líquida, as proporções dos ingredientes do xarope de aglutinação foram determinadas por meio de uma sequência de testes preliminares.

\subsubsection{Formulação final}

Os ingredientes para produção das barras de cereais, exceto o albedo, foram adquiridos no comércio da cidade de Sobral - CE. Os mesmos foram transportados para a planta piloto de Frutos do Instituto Federal de Educação, Ciência e Tecnologia do Ceará - Campus Sobral.

Os ingredientes da fase sólida foram compostos por: aveia em flocos, flocos de arroz, castanha de caju e farinha de albedo do maracujá (nas formulações BC 02, BC 03 e BC 04 em substituição da aveia em flocos de acordo a concentração de cada uma) e os ingredientes da fase líquida foram compostos por: gordura vegetal, açúcar mascavo, mel de abelha, xarope de glicose e polpa de maracujá, conforme descrito na Tabela 3.

Tabela 3 - Ingredientes das barras de cereais (Formulação final).

\begin{tabular}{|c|c|c|c|c|}
\hline \multirow[t]{2}{*}{ INGREDIENTES } & \multicolumn{4}{|c|}{ TRATAMENTOS } \\
\hline & BC 01 & BC 02 & BC 03 & ВС 04 \\
\hline \multicolumn{5}{|l|}{ Fase seca } \\
\hline Aveia em flocos & $20 \%$ & $17 \%$ & $13 \%$ & $9 \%$ \\
\hline Flocos de arroz & $12 \%$ & $12 \%$ & $12 \%$ & $12 \%$ \\
\hline Castanha de caju & $10 \%$ & $10 \%$ & $10 \%$ & $10 \%$ \\
\hline Albedo de maracujá & - & $3 \%$ & $7 \%$ & $11 \%$ \\
\hline \multicolumn{5}{|l|}{ Fase liquida } \\
\hline Xarope de glicose & $28,5 \%$ & $28,5 \%$ & $28,5 \%$ & $28,5 \%$ \\
\hline Açúcar mascavo & $10 \%$ & $10 \%$ & $10 \%$ & $10 \%$ \\
\hline Mel de abelha & $9 \%$ & $9 \%$ & $9 \%$ & $9 \%$ \\
\hline Gordura vegetal & $2 \%$ & $2 \%$ & $2 \%$ & $2 \%$ \\
\hline Polpa de maracujá & $8,5 \%$ & $8,5 \%$ & $8,5 \%$ & $8,5 \%$ \\
\hline Total $(\%)$ & 100 & 100 & 100 & 100 \\
\hline
\end{tabular}

BC 01 (barra de cereal com 0\% de albedo); BC 02 (barra de cereal com 3\% de albedo); BC 03 (barra de cereal com $7 \%$ de albedo); BC 04 (barra de cereal com $11 \%$ de albedo).

Fonte: Autores (2020).

A Figura 4 apresenta o fluxograma do preparo das barras de cereais. Antes de iniciar a produção das barras de cereais, todos os, móveis e utensílios, foram higienizados com água clorada a 0,04\%, em seguida foram pesados os ingredientes secos (aveia em flocos, flocos de arroz, castanha de caju e farinha de albedo do maracujá (nas formulações BC 02, BC 03 e BC 04 em substituição da aveia em flocos de acordo a concentração de cada uma).

Os ingredientes secos foram misturados e homogeneizados manualmente por 5 minutos e levados ao forno aquecido a $100^{\circ} \mathrm{C}$ por $15 \mathrm{~min}$. Já os ingredientes do xarope de aglutinação (exceto a polpa de maracujá) foram misturados e levados para o banho-maria $\left(100^{\circ} \mathrm{C} / 5 \mathrm{~min}\right)$. Decorrido esse tempo, os ingredientes secos e tostados foram adicionados ao xarope de aglutinação, permanecendo no banho-maria por mais 5 minutos, após 4 minutos destes foi adicionado a polpa de maracujá, continuando a misturá-los por mais 1 minuto. 
Figura 4 - Fluxograma das operações de processamento das barras de cereais.

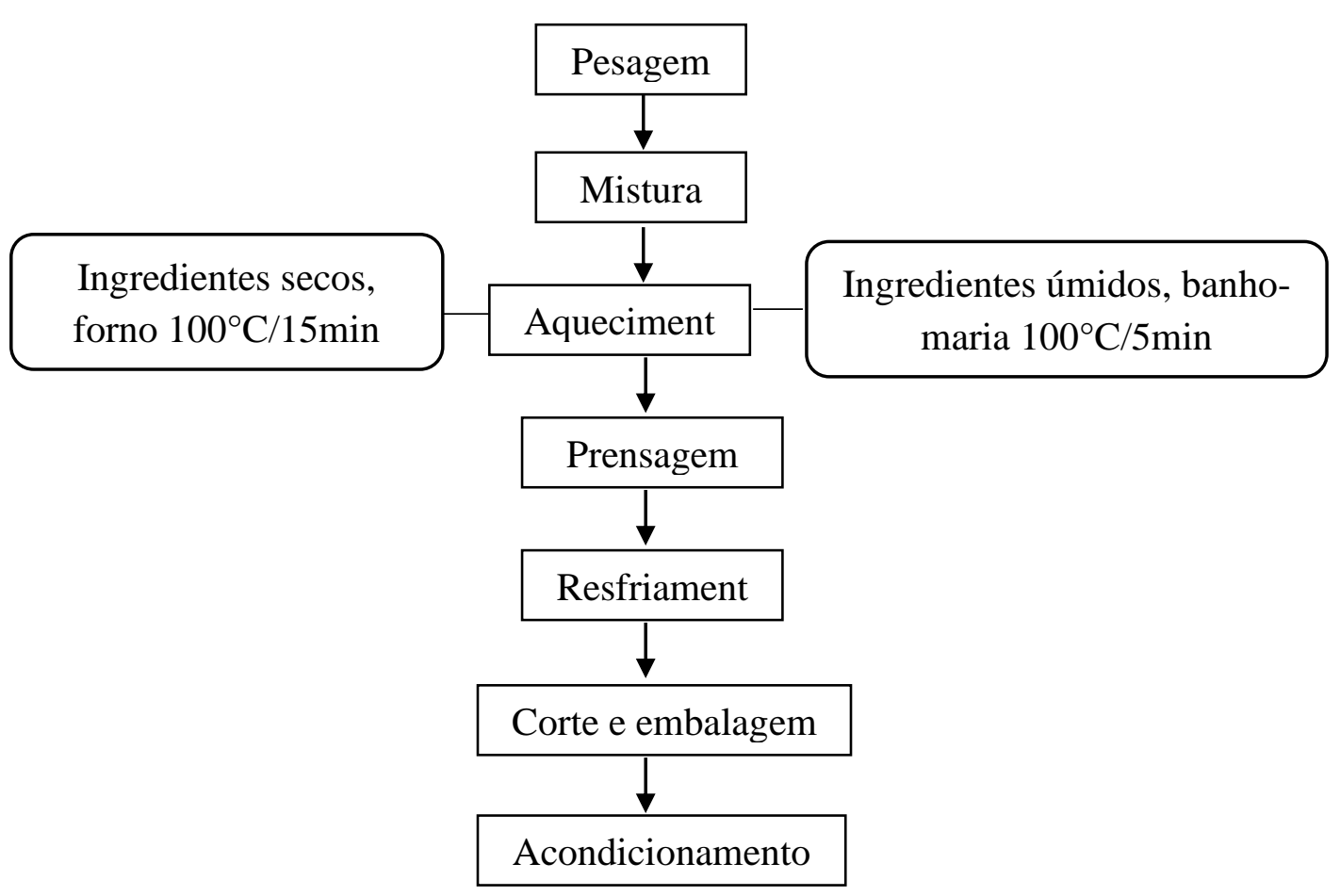

Fonte: Autores (2020)

Depois de misturados, os ingredientes secos e xarope formaram uma massa que foi prensada e moldada em forma envolvida com papel manteiga, onde permaneceu até atingir temperatura ambiente, separadamente, BC 01 (Figura 5A), BC 02 (Figura 5B), BC 03 (Figura 5C) e BC 04 (Figura 5D). Posteriormente, foram fracionadas (aproximadamente 14 gramas) e acondicionadas em papel manteiga, seladas e armazenadas em potes herméticos.

\subsection{Análises}

\subsubsection{Fisico-químicas}

A avaliação da cor das farinhas foi determinada com auxílio de colorímetro digital previamente calibrado (MiniSacn by HunterLab, modelo MIVISCAN EZ) com uma área de medição de $13 \mathrm{~mm}$ de diâmetro e geometria óptica de $45^{\circ} / 0^{\circ}$. O instrumento foi calibrado usando uma placa de calibração de branco padrão e a cor foi expressa de acordo com a Comissão Internacional de Iluminação (Sistema de cores $\mathrm{CIE} \mathrm{L} * \mathrm{a} * \mathrm{~b} *$ ). As leituras foram registradas com pelo menos seis repetições para cada formulação (em três lotes) em posições aleatórias. Os resultados foram calculados utilizando o equipamento na escala de cores Hunter Lab. Nesta escala, L* varia de 0 (preto) a 100 (branco); a* indica o grau de esverdeado (para valores negativos) e o grau de vermelhidão (para resultados positivos). $\mathrm{O}$ eixo $\mathrm{b}^{*}$ também varia de negativo a positivo, indicando valores, respectivamente, de azul a amarelo. $\mathrm{O}$ total diferença de cor $(\Delta \mathrm{E} *)$ foi calculada usando eqn (1) (Francis \& Clydesdale, 1975).

$$
\Delta E *=\sqrt{\left(\Delta L *^{2}+(\Delta a *)^{2}+(\Delta b *)^{2}\right.}
$$

Onde: $\Delta \mathrm{L}^{*}, \Delta \mathrm{a}^{*} \mathrm{e} \Delta \mathrm{b}^{*}$ são as diferenças entre as amostras em $\mathrm{L}^{*}, \mathrm{a}^{*} \mathrm{e} \mathrm{b}^{*}$, respectivamente. 
A interpretação deste resultado foi baseada na diferença total de cor perceptível pelo olho humano, tendo em vista que este só é capaz de distingue a diferença de cor se $1<\Delta \mathrm{E}^{*}<3$; porém, para algumas cores, principalmente azuis, valores $\Delta \mathrm{E}^{*}=$ 1 podem ser detectados, mas para outras cores, como vermelho, o mesmo $\Delta \mathrm{E}^{*}$ pode não ser perceptível (Bodart et al., 2008). De acordo com Mokrzycki e Tatol (2011) a percepção da diferença entre duas cores só é claramente percebida se 3,5 $<\Delta \mathrm{E} *<$ 5 , independente da experiencia do observador, se $1<\Delta \mathrm{E}^{*}<2$ apenas um observador experiente irá notar a diferença entre duas cores.

Figura 5 - Barras de cereais com diferentes concentrações.

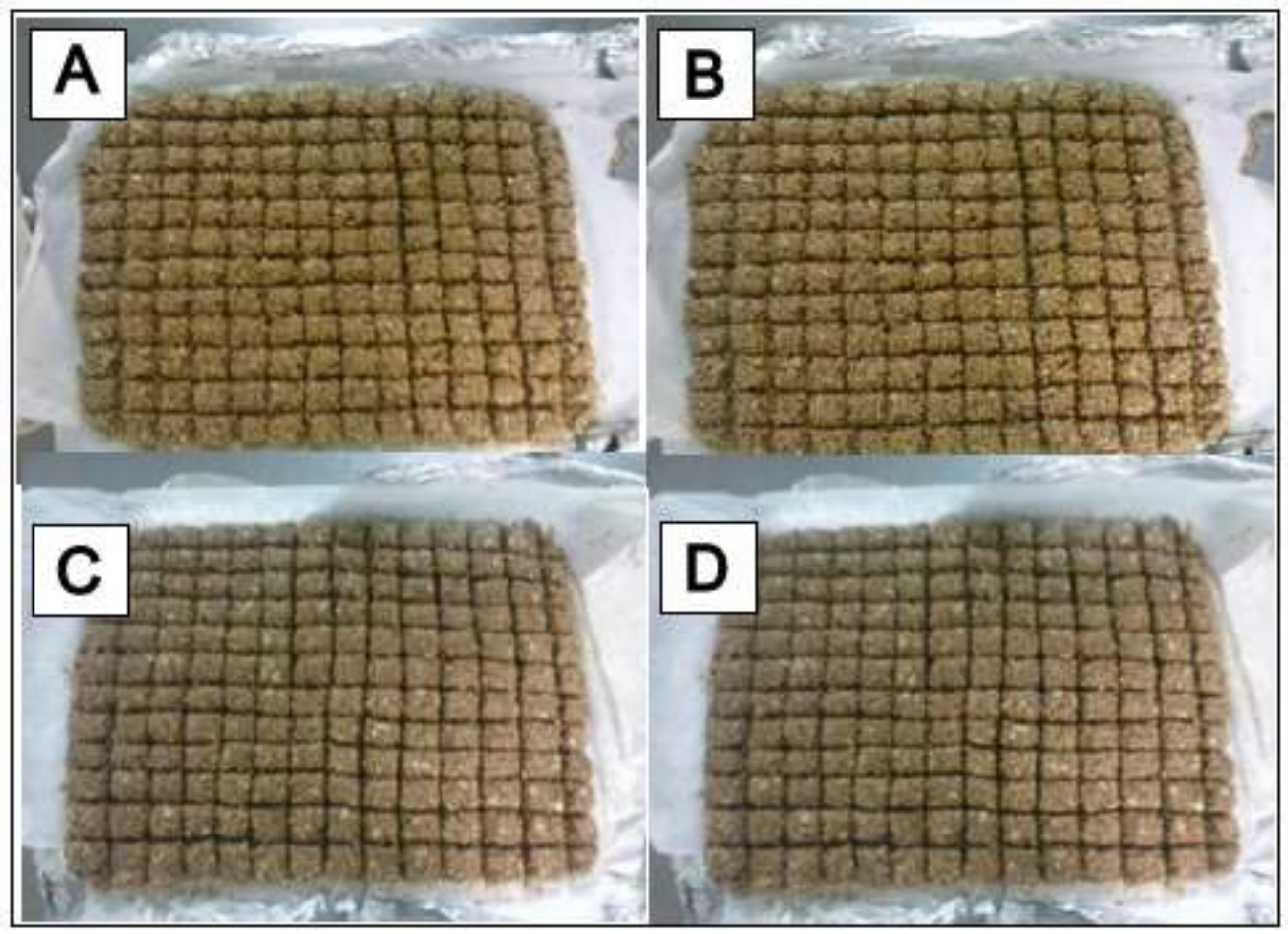

A - BC 01 (0\% de albedo). B - BC 02 (3\% de albedo). C - BC 03 (7\% de albedo). D - BC 04 (11\% de albedo).

Fonte: Autores (2020).

A atividade de água (Aw) das farinhas foi determinada por medida direta através de aparelho Aqualab Lite. Foram seguidas as metodologias propostas pela Association of Official Analytical Chemists (AOAC, 2000).

Para a caracterização físico-química das amostras de farinhas e das barras de cereais foram realizadas as seguintes análises: umidade, determinada pelo método gravimétrico de perda de massa por dessecação; cinzas, determinado submetendo as amostras a um processo de carbonização prévia seguida de incineração completa em mufla a temperatura de $550^{\circ} \mathrm{C}$ por 6 horas; proteínas, determinado por destilação de nitrogênio orgânico (Micro-Kjeldahl); Lipídeos determinado pela extração com solventes (Hexano) em extrator de Soxhlet fibras que foi determinado por digestão ácida seguida de digestão alcalina da amostra seca desengordurada por 30 minutos a cada digestão; o teor de carboidratos que foi calculado a partir da diferença dos teores de umidade, cinzas, proteínas, lipídios. Para o cálculo do valor calórico das barras de cereais foram utilizados fatores de conversão de Atwater: 4 kcal/g (proteína), 4 kcal/g (carboidratos) e 9 kcal/g (lipídios) (Brasil, 2001a).

\subsubsection{Análise microbiológicas}

As análises microbiológicas das barras de cereais foram realizadas no laboratório de microbiologia, no Instituto Federal de Educação, Ciência e Tecnologia do Ceará - IFCE, Campus Sobral. 
As análises microbiológicas foram realizadas conforme metodologia descrita pelo Manual de métodos de análises microbiológicas de alimentos (Silva et al., 2001). Foram realizadas as seguintes análises: Coliformes Termotolerantes e Coliformes Totais, sendo as de Coliformes Termotolerantes indicada para cereais estabelecido pela Resolução RDC ${ }^{\circ} 12$ de 02 de janeiro de 2001 da Agência Nacional de Vigilância Sanitária (Brasil, 2001b).

\subsubsection{Análise sensorial}

Os testes foram aplicados no laboratório de Análise Sensorial do Eixo de Produção Alimentícia do curso de tecnologia em Alimentos do Instituto Federal de Educação, Ciência e Tecnologia - IFCE, Campus Sobral onde apresenta estrutura adequada para a realização dos testes, pois dispõe de cabines individuais, com iluminação adequada e sala climatizada. Foi aplicado o teste de aceitação, com escala hedônica estruturada de 9 pontos, onde 9 representava a nota máxima "gostei extremamente" e 1 a nota mínima "desgostei extremamente". Os provadores avaliaram os atributos cor, aroma, textura, sabor, impressão global e intenção de compra do produto com o objetivo de verificar sua aceitação do produto pelos consumidores.

A equipe sensorial foi composta por 60 provadores não treinados entre estudantes, funcionários e professores do Instituto Federal de Educação, Ciência e Tecnologia do Ceará - Campus Sobral. A amostra foi codificada aleatoriamente com três dígitos e foi servida em copos plásticos descartáveis de $50 \mathrm{~mL}$ a temperatura ambiente, em cabines individuais e na forma de blocos completos casualizados. As amostras foram acompanhadas de copo d'água e da ficha de avaliação.

\subsubsection{Análise estatística}

Todas as análises foram realizadas em triplicata. Os dados obtidos foram avaliados estatisticamente através de valores médios, desvio padrão e Análise de Variância (ANOVA), utilizando uma margem de 5\% de significância e teste Tukey, para as amostras diferentes. Utilizou-se como ferramenta o programa Sisvar versão 5.01 e Statisca 7.0, para as físico-químicas foram analisados as médias e desvio padrão como ferramenta o programa Microsoft Excel 2010.

\section{Resultados e Discussão}

\subsection{Rendimento da desidratação do albedo}

Após desidratação do albedo o rendimento de farinha foi de 9,28\%, visto que para 4.754,62 gramas de albedo de maracujá amarelo (Passiflora edulis f. flavicarpa), foram obtidas, 441,15 gramas de farinha de albedo. Esse rendimento obtido mostra-se próximo ao alcançado por Oliveira (2009), onde obteve rendimento de 10,3\% de farinha em relação ao albedo de maracujá.

No que diz respeito ao albedo, o rendimento encontrado para 9.820,89 gramas de maracujás foi de 48,41\%, correspondente as 4.754,62 gramas de albedo, percentagem também próxima a alcançada por Oliveira (2009), que obteve rendimento de $51,25 \%$ de albedo em relação ao fruto do maracujá.

\subsection{Caracterização das Farinhas de Maracujá}

Os resultados da análise físico-química das farinhas de maracujá (P.edulis) comerciais e produzida a partir do albedo estão descritos na Tabela 4. 
Tabela 4 - Caracterização físico-química das farinhas de albedo de maracujá (Média \pm DP).

\begin{tabular}{|c|c|c|c|c|c|}
\hline \multirow[b]{2}{*}{ ANÁLISES } & \multicolumn{5}{|c|}{ AMOSTRAS } \\
\hline & FAMF & FMAW & FMAY & FMAX & FMAZ \\
\hline$L^{*}$ & $76,61 \pm 0,45^{a}$ & $61,31 \pm 0,36^{c}$ & $61,08 \pm 0,55^{c}$ & $67,10 \pm 0,51^{b}$ & $57,23 \pm 0,11^{d}$ \\
\hline$a^{*}$ & $8,37 \pm 0,24^{b}$ & $6,69 \pm 0,32^{a}$ & $9,94 \pm 0,22^{a}$ & $06,69 \pm 0,32^{c}$ & $10,10 \pm 0,01^{a}$ \\
\hline$b^{*}$ & $30,00 \pm 0,74^{a}$ & $27,2 \pm 0,17^{c}$ & $28,83 \pm 0,39^{b}$ & $23,22 \pm 0,36^{d}$ & $28,10 \pm 0,03^{b c}$ \\
\hline Aw & $0,20 \pm 0,003^{\mathrm{e}}$ & $0,28 \pm 0,002^{\mathrm{c}}$ & $0,30 \pm 0,004^{\mathrm{b}}$ & $0,36 \pm 0,005^{\mathrm{a}}$ & $0,26 \pm 0,003^{\mathrm{d}}$ \\
\hline Umidade & $7,52 \pm 0,26^{\mathrm{c}}$ & $9,43 \pm 0,06^{\mathrm{b}}$ & $9,10 \pm 0,06^{\mathrm{b}}$ & $11,45 \pm 0,55^{\mathrm{a}}$ & $9,20 \pm 0,03^{b}$ \\
\hline Cinzas & $6,13 \pm 0,01^{\mathrm{a}}$ & $3,38 \pm 0,04^{\mathrm{d}}$ & $5,16 \pm 0,03^{b}$ & $03,20 \pm 0,08^{\mathrm{e}}$ & $5,00 \pm 0,04^{\mathrm{c}}$ \\
\hline Proteína & $3,85 \pm 2,26^{\mathrm{b}}$ & $7,37 \pm 0,43^{\mathrm{a}}$ & $7,06 \pm 0,70^{\mathrm{a}}$ & $09,06 \pm 0,78^{\mathrm{a}}$ & $7,61 \pm 0,34^{\mathrm{a}}$ \\
\hline Lipídios & $0,40 \pm 0,12^{\mathrm{d}}$ & $2,28 \pm 0,11^{\mathrm{b}}$ & $2,27 \pm 0,16^{\mathrm{b}}$ & $01,70 \pm 0,02^{\mathrm{c}}$ & $3,18 \pm 0,24^{\mathrm{a}}$ \\
\hline Fibra Bruta & $67,30 \pm 3,45^{\mathrm{a}}$ & $16,00 \pm 0,46^{\mathrm{dc}}$ & $22,71 \pm 0,02^{\mathrm{b}}$ & $13,40 \pm 0,19^{\mathrm{e}}$ & $22,13 \pm 0,74^{\mathrm{cb}}$ \\
\hline Carboidrato & $81,03 \pm 0,93^{\mathrm{a}}$ & $81,03 \pm 0,93^{\mathrm{a}}$ & $81,03 \pm 0,93^{\mathrm{a}}$ & $81,03 \pm 0,93^{\mathrm{a}}$ & $81,03 \pm 0,93^{\mathrm{a}}$ \\
\hline
\end{tabular}

FAMF: Farinha de albedo de maracujá produzida no laboratório; FMAW: Farinha de maracujá de marca W; FMAY: Farinha de maracujá de marca Y; FMAX: Farinha de maracujá de marca X; FMAZ: Farinha de maracujá de marca Z. Letras iguais na mesma linha, não há diferença significativa pelo teste de Tukey, ao nível de $5 \%$ de significância.

Fonte: Autores (2020).

Os resultados do teste de cor $\left(\mathrm{L}^{*}, \mathrm{a}^{*}\right.$ e $\mathrm{b}^{*}$ ) (Tabela 4) mostram que houveram diferença significativa entre as amostras, sendo que a farinha de albedo do maracujá apresentou coloração mais clara, podendo ser percebida visualmente. A cor é uma característica sensorial dos alimentos, que muitas vezes leva a escolha de um determinado produto em detrimento de outro pelo consumidor. Desta forma a FAMF pode ser utilização em formulações alimentícias, pois não causará uma interferência no quesito sensorial relacionado à cor. Em relação aos valores de cromaticidade (a* e b*), mesmo havendo diferença estatística entre as amostras, verifica-se que as farinhas apresentaram variação de cor na região do amarelo (b*) com traços de vermelho $\left(\mathrm{a}^{*}\right)$, resultados semelhantes foram descritos por Silva (2017), o qual verificou que tanto as farinhas de albedo macerada e não macerada tendia a essa mesma cor.

Em estudo realizado por Lopéz-Vargas et al. (2013) quando comparou pó obtidos de coprodutos do maracujá como albedo e de sementes e polpa, verificou diferença significativa na cor dos mesmos, sendo que o pó do albedo apresentava uma maior luminosidade, tendo assim uma cor mais clara ( $\left.\mathrm{L}^{*} 79,91\right)$ que do que o pó obtido da semente e polpa (L* 43,89), corroborando com o resultado da FAMF do presente estudo. Isso mostra que a parte da qual a farinha foi produzida pode influenciar na sua cor. Vale ressaltar também que o tempo de armazenamento pode inferir na mudança de cor do produto, tendendo este a ficar mais escuras $\left(<\mathrm{L}^{*}\right)$, menos amarela $\left(<\mathrm{b}^{*}\right)$ e aumento de pigmentos avermelhados $\left(>\mathrm{a}^{*}\right)$ quanto maior for o tempo de armazenamento (Reolon, 2008).

Ao comparar a diferença de cor $\left(\Delta \mathrm{E}^{*}\right)$ da farinha produzida a partir do albedo do maracujá (FAMF) com as farinhas comerciais (FMAX, FMAW, FMAY e FMAZ) os resultados encontrados foram de 11,83 \pm 0,62; 15,60 \pm 0,72; 15,68 \pm 0,97 e 19,59 \pm 0,38, respectivamente, assim a diferença de cor é notada percebida pelo observador, mesmo sem experiencia, sendo esta diferença maior ente FAMF $\rightarrow$ FMAZ. Desta forma o uso de FAMF em alimentos irá gerar menor alteração na cor do alimento quando incorporada que as demais.

No entanto ao comparar as farinhas comerciais entre si, obteve-se valores de 7,67 $\pm 0,68 ; 8,87 \pm 0,59 ; 11,53 \pm 0,54$; $1,65 \pm 0,40 ; 4,20 \pm 0,36 ; 3,93 \pm 0,69$, para FMAX $\rightarrow$ FMAW, FMAX $\rightarrow$ FMAY; FMAX $\rightarrow$ FMAZ; FMAW $\rightarrow$ FAMY; 
FMAW $\rightarrow$ FMAZ; e FMAY $\rightarrow$ MFAZ, respectivamente. Estes valores mostram que as farinhas comerciais apresentam cor perceptivelmente diferentes a olho nu, porém esta diferença é menos perceptível entre FMAW $\rightarrow$ FAMY, assim só um observador experiente perceberá a diferença entre elas.

\subsection{Caracterização das Barras de Cereais}

Os resultados médios das porcentagens de proteínas, cinzas, umidade, lipídios, fibras, carboidratos e valor calórico estão dispostos na Tabela 5.

As proteínas são nutrientes essenciais para a nutrição humana, por exercerem funções muito importantes no organismo, como auxiliar na construção de tecidos e na formação de enzimas, como as enzimas digestivas e hormônios, como a insulina.

Conforme Tabela 5, nota-se que a medida que vai aumentando a concentração de farinha de albedo de maracujá, vai aumentando também a quantidade de proteína nas barras.

Foi observado que esse percentual proteico entre as barras variando entre $5,65 \%$ e $8,62 \%$, foi superior ao encontrado por Costa et al., (2005) e por Silva et al., (2009), que encontraram teores de proteínas respectivamente 4,4\% e 4,3\%, e próximos aos encontrados por Dutcosky et al. (2006) e Silveira et al., (2014), onde relataram 5,5\%; 8,50 respectivamente.

Portanto, as barras formuladas se apresentaram com teor de proteínas superior as barras comerciais, que de acordo com Freitas e Moretti (2006), os produtos encontrados no mercado apresentam, em média, 4,4\% de proteínas, mostrando-se então com alto teor proteico.

A determinação de cinzas fornece uma indicação da riqueza de elementos minerais da amostra, sendo constituída principalmente de grandes quantidades de $\mathrm{K}, \mathrm{Na}, \mathrm{Ca}$ e Mg; pequenas quantidades de $\mathrm{Al}, \mathrm{Fe}, \mathrm{Cu}, \mathrm{Mn}$ e $\mathrm{Zn}$ (Silva \& Queiroz, 2002).

Tabela 5 - Caracterização de Barras de cereais (Média \pm DP).

\begin{tabular}{ccccc} 
Análises & \multicolumn{4}{c}{ Tratamentos } \\
\cline { 2 - 5 } & BC 01 & BC 02 & BC 03 & BC 04 \\
Proteína (\%) & $5,65 \pm 0,72$ & $6,95 \pm 0,72$ & $8,35 \pm 0,72$ & $8,62 \pm 0,72$ \\
Cinzas (\%) & $0,88 \pm 0,16$ & $0,99 \pm 0,16$ & $1,24 \pm 0,16$ & $1,37 \pm 0,16$ \\
Umidade (\%) & $9,41 \pm 0,50$ & $8,26 \pm 0,50$ & $12,77 \pm 0,50$ & $13,15 \pm 0,50$ \\
Lipídios (\%) & $3,89 \pm 0,28$ & $3,53 \pm 0,28$ & $3,36 \pm 0,28$ & $2,53 \pm 0,28$ \\
Carboidratos (\%) & $59,27 \pm 0,05$ & $58,30 \pm 0,05$ & $51,54 \pm 0,05$ & $50,60 \pm 0,05$ \\
Valor Calórico (Kcal) & $294,69 \pm 0,05$ & $292,77 \pm 0,05$ & $269,80 \pm 0,05$ & $259,65 \pm 0,05$ \\
\hline
\end{tabular}

BC 01 (barra de cereal com 0\% de albedo); BC 02 (barra de cereal com 3\% de albedo); BC 03 (barra de cereal com $7 \%$ de albedo); BC 04 (barra de cereal com $11 \%$ de albedo).

Fonte: Autores (2020).

Conforme a Tabela 5 pode-se observar teores de cinzas obtido de $0,88 \%$ a $1,37 \%$. Esse resultado indica uma quantidade significativa de presença de minerais. Se mostram próximo aos valores encontrados por Cichaczewski (2012), que ao avaliar o teor de cinzas em barra de cereal rica em fibras a partir do subproduto da extração do suco de maçã obteve valores entre 0,75 e 1,36 . 
Valores similares foram encontrados por Brito et al. (2004) (1,13\%) e por Bueno (2005) (1,18\%); já Guimarães (2007) encontrou valores entre 1,1 a 1,3 g/100 g, ao analisar barras de cereais formuladas com frutas secas, buriti e banana passa, em diferentes formulações; e Ambrosio-Ugri e Ramos (2012), ao elaborar barra de cereais com substituição parcial de aveia por farinha da casca de maracujá encontrou teor de cinzas de $0,83 \%$, valor bem próximo do encontrado na formulação BC $01(0,88 \%)$.

Com relação a umidade, um aspecto importante a ser considerado é que permite a manutenção da crocância (Sarantópoulos et al., 2001). Essas condições também inferem no não favorecimento a proliferação microbiana, sendo a umidade o principal fator para o desenvolvimento de fungos, leveduras e bactérias.

Os teores de umidade obtidos para cada formulação de barra de cereal apresentaram diferença significativa. Os valores variaram entre $8,26 \%$ a $13,15 \%$, estes valor conferem boa estabilidade físico-química ao produto, com um tempo de conservação longo, desde que armazenado adequadamente.

Segundo a Resolução RDC n 263, de 22 de setembro de 2005 (Brasil, 2005), a umidade de barras de cereais deve ser inferior a $15,0 \%$. Portanto, os resultados obtidos indicam que o produto desenvolvido atendeu aos requisitos de umidade pela legislação.

Os teores de umidade encontrados (8,26\% a 13,15\%) foram próximos ao encontrado por Brito et al. (2004), Matsuura (2005), Freitas et al. (2006), Bueno et al. (2005), Ambrosio-Ugri e Ramos (2012), correspondentes a 7,63\%; 8,0\%; 10,7 \%; 12\%; e 13,09\%; superior ao encontrado por Coelho (2006) igual a 6,92\% e inferior ao encontrado por Torres (2009) que foi $18,56 \%$ para barra de cereal com pó de jaca e 23,46\% para barra de cereal com jenipapo seco. Essa variação provavelmente, é devida aos componentes utilizados na preparação das barras.

De acordo com Ribeiro (2003), alguns microrganismos estão envolvidos no processo de deterioração em cereais e seus produtos, os quais se desenvolvem sempre que encontram condições favoráveis de umidade e temperatura.

Em se tratando de lipídios, são compostos orgânicos altamente energéticos que contêm ácidos graxos essenciais ao organismo e atuam como transportadores das vitaminas lipossolúveis.

Com relação ao conteúdo de lipídios, observou-se que o produto apresentou valores de 2,53\% a 3,89\%. Segundo Sampaio et al. (2004), no mercado são encontrados produtos com teores que variam de 4,0 \% a 12,0 \%.

Logo, pode-se constatar que a formulação elaborada apresenta baixo conteúdo lipídico, o que pode ser uma característica relevante, uma vez que os lipídios contribuem grandemente para o aumento do conteúdo calórico de um alimento.

$\mathrm{Na}$ literatura podem ser encontrados teores que variam de 0,68\% por Brito et. al., (2004); 5,64\% por Freitas e Moretti, (2006) para barras de cereais sem adição de cobertura de chocolate. Baú et al. (2002) ao elaborar e avaliar barra alimentícia com elevado valor proteico, obteve teor de lipídios de apenas 2,23\%, valor relativamente baixo, e próximo ao encontrado na formulação BC 04, contendo $11 \%$ de farinha de albedo de maracujá (2,52\%).

A respeito das fibras, as fibras alimentares ajudam na manutenção da flora intestinal, produção de substâncias que estimulam o sistema imunitário, estimula a motilidade intestinal (trânsito intestinal) e ajuda o intestino a absorver as substâncias necessárias, eliminando o excesso de glucose e colesterol (principalmente o LDL - mau colesterol) e triglicerídeos no sangue.

Além disso, tem sido também, relacionada à redução dos níveis de glicose no sangue, sendo indicada como auxiliar no tratamento do diabetes.

Segundo Matsuura (2005), dentre as fibras solúveis do albedo do maracujá, destaca-se a pectina. Esta substância apresenta-se em grande quantidade na casca do maracujá e pesquisas recentes vêm demonstrando que ela é capaz de reduzir o 
LDL (colesterol ruim) e aumentar o HDL (bom colesterol). Dessa forma, a barra de cereal adicionada da farinha de albedo de maracujá poderá apresentar múltiplas funcionalidades ao organismo humano.

Os valores obtidos nas formulações BC 01, BC 02, BC 03 e BC 04 foram de 20,90\%; 21,97\%; 22,74 e 23,73\% respectivamente o que é considerado um resultado excelente.

De acordo com a Portaria n ${ }^{\circ} 27$ de 13 de janeiro de 1998, as barras de cereais são classificadas como "fonte de fibra" por conterem quantidade superior ao teor mínimo de $3 \%$ de fibra.

O teor de fibra bruta observada aumenta com o aumento da concentração da farinha de albedo de maracujá em cada formulação. Os resultados foram superiores aos encontrados nos trabalhos de Brito et al. (2004) que apresentou o valor 3,44\% e Carvalho (2008) em que os teores de fibras das barras de cereais do seu estudo variaram entre 2,8 a $3 \%$; também se mostraram superiores a 7,96\% encontrados por Becker e Kruger (2010).

Essa grande quantidade de fibras presente nas barras formuladas, principalmente as pectinas, não possuem efeito laxativo, sendo na maior parte degradada pela flora bacteriana no cólon, tendo como resultado o efeito probiótico.

Os alimentos ricos em carboidratos, como os pães, barras de cereais, arroz e massas, são uma importante forma de energia para o organismo e, por isso, são muito importantes para uma alimentação saudável.

Os valores obtidos para o teor de carboidratos nas formulações BC 01, BC 02, BC 03 e BC 04 foram de 59,27\%; $58,30 \% ; 51,54 \%$ e $50,60 \%$ respectivamente.

Esses valores foram inferiores a Freitas et al., (2006) que encontrou uma quantidade de 60,97\% de carboidratos. Já Marques (2013) obteve valor de 54,58\%, estando este próximo aos encontrados nas barras formuladas.

Entretanto, os carboidratos além de serem de grande importância para alimentação, no entanto, quando consumidos em excesso, aumentam a quantidade de gordura corporal, causando problemas a saúde.

Os teores baixos encontrados nas barras formuladas, quando comparadas com demais, podem ser consideradas ideais para diabéticos e também pessoas que realizam regime de emagrecimento.

Com relação ao valor energético, conforme a Tabela 5 pode-se observar teores de valor calórico obtido de 294,69 $\mathrm{Kcal} / 100 \mathrm{~g} ; 292,77 \mathrm{Kcal} / 100 \mathrm{~g} ; 269,80 \mathrm{Kcal} / 100 \mathrm{~g}$ e 259,65 Kcal/100g, para as amostras BC 01, BC 02, BC 03 e BC 04 respectivamente, indicando baixo valor calórico.

Comparando os dados encontrados com a literatura, o valor calórico das barras de cereais elaboradas por Brito et al. (2004) do tipo caseira (354,6 Kcal/100g); Costa et al. (2005) a base de resíduo da fabricação de farinha de mandioca (387,9 $\mathrm{Kcal} / 100 \mathrm{~g}$ ) e Silva et al., (2009) adicionada de resíduo industrial de maracujá (344,2 Kcal/100g), possuem teores energéticos superiores ao encontrado nas barras de cereais formuladas.

O baixo teor energético encontrado nas barras formuladas se justifica pelo menor conteúdo de carboidratos $(59,27 \%$ a $50,60 \%)$ e lipídios (2,53\% a 3,89\%) comparado aos valores encontrados por outros autores (Gutkoski et al., 2007; Freitas \& Moretti, (2006), Sampaio et al. (2004), o que representa um bom resultado podendo os consumidores consumirem mais barras.

Foi observado também, que houve uma redução no teor calórico à medida que foram aumentadas as concentrações do albedo de maracujá.

Levando em consideração que uma barra de cereal tem em média $25 \mathrm{~g}$, os valores obtidos ficaram entre 73,67 kcal e $64,91 \mathrm{kcal}$, representando assim menos de $5 \%$ do valor recomendado diariamente, podendo as mesmas serem consumidas tranquilamente.

Ressalta-se que para uma mulher a média para o valor calórico é de 2000 kcal por dia e para um homem é de 2500 kcal por dia. Estes valores são usados como referência para calcular os valores diários de referência para os nutrientes (Brasil, 2001a.). 
Portanto, a substituição parcial da aveia em flocos pela farinha de albedo é possível nutricionalmente pois esta substituição não elevou o valor calórico das barras de cereais.

\subsection{Análise Microbiológica}

As análises microbiológicas foram realizadas nas amostras BC 01 e BC 02 por terem sido as mais aceitas na análise sensorial (Tabela 6).

Tabela 6 - Resultados das análises microbiológicas das barras de cereais.

\begin{tabular}{llll}
\hline Análise & BC 01 & BC 02 & Referência* \\
\hline Coliformes Termotolerantes a $45^{\circ} \mathrm{C}$ & - & - & $5 \times 10$ \\
Coliformes Totais a $35^{\circ} \mathrm{C}$ & $3,0 \mathrm{NMP} * * / \mathrm{mL}$ & $3,0 \mathrm{NMP} * * / \mathrm{mL}$ & $-* * *$ \\
\hline
\end{tabular}

*Resolução - RDC $\mathrm{n}^{\circ} .12$, de 02 de janeiro de 2001 da ANVISA Grupo de alimentos 10 - Farinhas, Massas alimentícias, produtos de panificação (industrializados e embalados) e similares (cereais compactados, em barra ou outras formas com ou sem adição). **NMP: Número Mais Provável ***Não estabelecido pela resolução.

Fonte: Autores (2020).

De acordo com os resultados apresentados na Tabela 6 e com base na Resolução da ANVISA RDC n ${ }^{\circ} 12$. de 02 de janeiro de 2001, as formulações BC 01 e BC 02 seguiram as boas práticas higiênicos de manipulação de alimentos.

A Resolução estabelece para barras de cereais, entre outros, padrões microbiológicos para Coliformes Termotolerantes, onde o máximo permitido é de 5 NMP/g (Brasil, 2001b).

Os dois tratamentos estão de acordo com a legislação vigente já que não apresentaram valores para Coliformes Termotolerantes. A legislação vigente não exige a análise de coliformes totais, entretanto esta indica as condições higiênicosanitárias dos alimentos. Nesse experimento os valores se mantiveram em $3 \mathrm{NMP} / \mathrm{mL}$.

\subsection{Análise Sensorial}

Os resultados da avaliação sensorial das formulações de barra de cereais estão apresentados na Tabela 7 a seguir.

Tabela 7 - Valores hedônicos médios para cor, aroma, textura, sabor e impressão global das formulações de barras de cereais.

\begin{tabular}{cccccc}
\hline Tratamento & Cor & Aroma & Textura & Sabor & Impressão Global \\
\hline BC 01 & $7,27^{\mathrm{a}} \pm 0,16$ & $7,22^{\mathrm{a}} \pm 0,16$ & $6,55^{\mathrm{a}} \pm 0,20$ & $7,62^{\mathrm{a}} \pm 0,22$ & $7,23^{\mathrm{a}} \pm 0,20$ \\
BC 02 & $7,42^{\mathrm{a}} \pm 0,16$ & $7,20^{\mathrm{a}} \pm 0,16$ & $6,72^{\mathrm{a}} \pm 0,20$ & $6,92^{\mathrm{a}} \pm 0,22$ & $7,03^{\mathrm{ab}} \pm 0,20$ \\
BC 03 & $7,30^{\mathrm{a}} \pm 0,16$ & $6,93^{\mathrm{a}} \pm 0,16$ & $6,58^{\mathrm{a}} \pm 0,20$ & $5,77^{\mathrm{b}} \pm 0,22$ & $6,38^{\mathrm{b}} \pm 0,20$ \\
BC 04 & $7,12^{\mathrm{a}} \pm 0,16$ & $6,55^{\mathrm{b}} \pm 0,16$ & $6,38^{\mathrm{a}} \pm 0,20$ & $4,78^{\mathrm{c}} \pm 0,22$ & $5,60^{\mathrm{c}} \pm 0,20$ \\
\hline
\end{tabular}

BC 01 (barra de cereal com 0\% de albedo); BC 02 (barra de cereal com 3\% de albedo); BC 03 (barra de cereal com $7 \%$ de albedo); BC 04 (barra de cereal com $11 \%$ de albedo). *Letras diferentes na mesma colona diferem significativamente pelo teste de Tukey ( $\leq \leq 0,05)$.

Fonte: Autores (2020).

Conforme a Tabela 7, em relação aos atributos cor, observou-se que a substituição à aveia não foi percebida pelos provadores, ou seja, não houve diferença significativa entre as amostras.

Ainda observando a Tabela 7, em relação aos atributos aroma, textura, sabor e impressão global observa-se que houve diferença significativa entre as amostras. Isso mostra que a substituição parcial de farinha da casca de maracujá pela aveia nas barras de cereais, causa uma diferença no aroma e sabor do produto, sendo perceptível aos provadores. 
Essa diferença pode ser em função do aumento da adstringência das barras com o aumento percentual de farinha de maracujá na formulação. Esse aumento, foi observado também por Silva et al., (2009), que indica a presença de taninos como principal causador de tal adstringência.

Em virtude disso, observa-se que o atributo "sabor" da formulação BC 04 foi o atributo que apresentou as menores médias, indicando que a adição da maior quantidade de farinha de maracujá, ou seja, $11 \%$ de albedo de maracujá amarelo o alterou, consequentemente, afetando a aceitação global dessa formulação por parte dos provadores.

Essa diferença pode ser em função do aumento da adstringência das barras com o aumento percentual de farinha de maracujá na formulação. Esse aumento, foi observado também por Silva, Oliveira, Lopes \& Pena (2009), que indica a presença de taninos como principal causador de tal adstringência.

Em virtude disso, observa-se que o atributo "sabor" da formulação BC 04 foi o atributo que apresentou as menores médias, indicando que a adição da maior quantidade de farinha de maracujá, ou seja, 11\% de albedo de maracujá amarelo o alterou, consequentemente, afetando a aceitação global dessa formulação por parte dos provadores.

Com relação aos resultados da escala hedônica que varia dos extremos 1 (desgostei extremamente) ao extremo 9 (gostei extremamente), pode ser verificado na Figura $6 \mathrm{em}$ se tratando do atributo cor que, (56,7\%) dos provadores indicaram terem "gostado extremamente" e "gostado muito" da cor da formulação BC 01; (57\%) da formulação BC 02; (45\%) formulação BC 03 e $(48,4 \%)$ formulação BC 04 . Vale ressaltar que nenhum provador "desgostou muito" ou "desgostou extremamente" do atributo cor, e apenas 6,6\% "desgostaram ligeiramente", e 1,7\% "desgostaram moderadamente".

Para o atributo aroma observa-se que à medida que a concentração de farinha de albedo vai sendo aumentada, os provadores vão percebendo significativamente.

Foi observado que $50 \%$ dos provadores afirmam "gostarem extremamente" e "gostado muito" da amostra BC 01, valor próximo ao obtido na amostra BC 02 com 45,3\%; já para as amostras BC 03 e BC 04, os encontrados foram de 33,3\% e $25 \%$ respectivamente. 
Figura 6 - Resultado da escala hedônica dos parâmetros sensoriais (cor, aroma, textura e sabor).

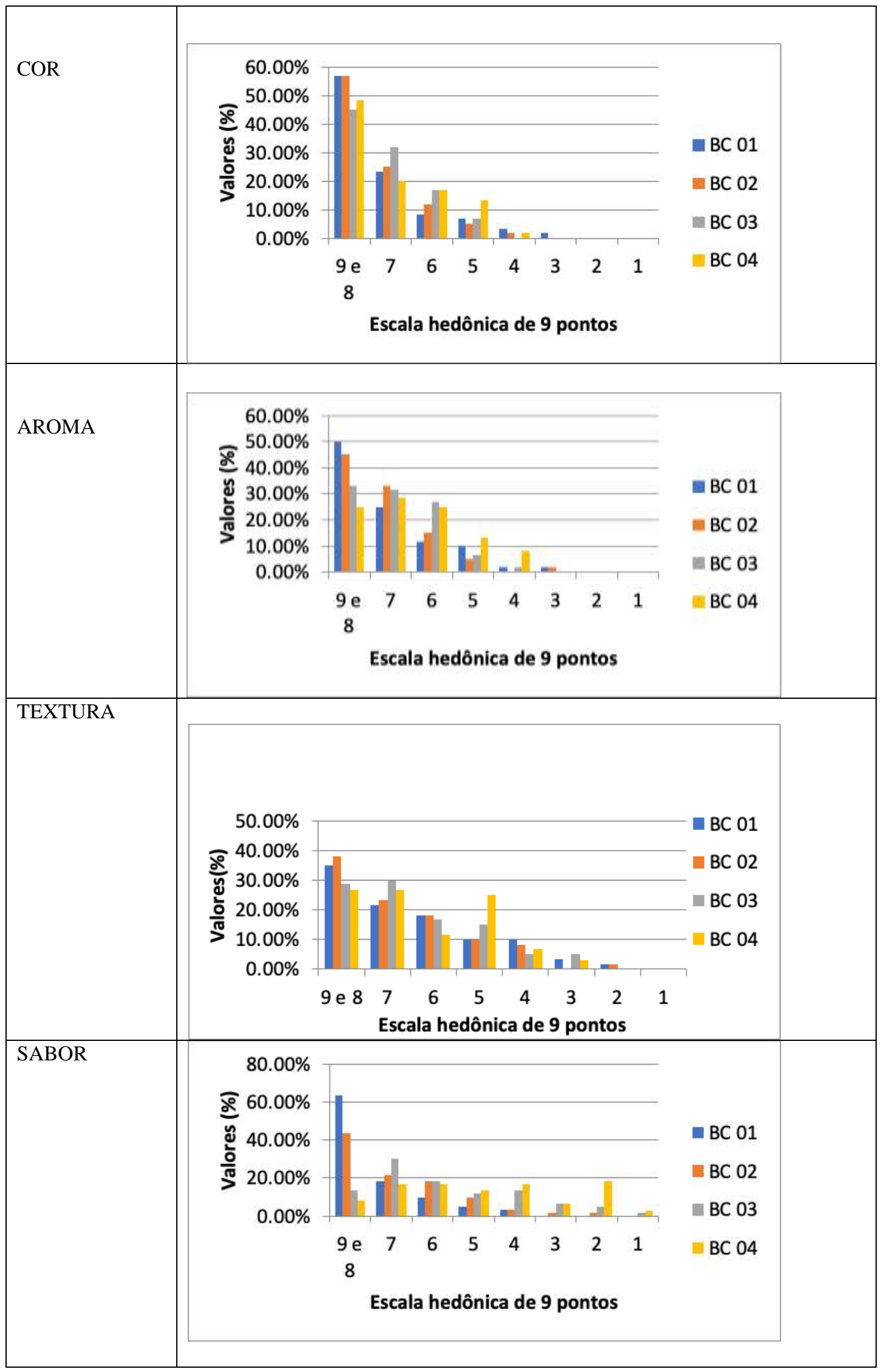

Fonte: Autores (2020). 
$\mathrm{O}$ atributo textura foi o que recebeu menores números de aprovação dos provadores como "gostei extremamente" e "gostei muito", tendo obtido valores de 35\%; 38,3\%; $28,7 \%$ e 26,7\% para as formulações BC 01, BC 02, BC 03 e BC 04 respectivamente.

$\mathrm{O}$ atributo textura foi o que recebeu menores números de aprovação dos provadores como "gostei extremamente" e "gostei muito", tendo obtido valores de 35\%; 38,3\%; 28,7\% e 26,7\% para as formulações BC 01, BC 02, BC 03 e BC 04 respectivamente.

A composição das barras pode ter levado a textura da barra não ter sido tão bem aceita, uma vez que as formulações foram constituídas de $58 \%$ de ingredientes úmidos, e $42 \%$ de ingredientes sólidos, tendo esse fator interferido na textura final da barra.

Em relação ao atributo sabor $63,3 \%$, dos provadores afirmaram terem "gostado extremamente" e "gostado muito" da formulação BC 01, em contrapartida 43,4\% afirmaram gostar extremamente e gostado muito da amostra BC 02. Já para as amostras BC 03 e BC 04, 13,4\% e 8,4\% dos provadores afirmaram terem "gostado extremamente" e "gostado muito", valores muito abaixo dos obtidos nas formulações BC 01 e BC 02.

A grande maioria dos provadores comentou que sentiu sabor amargo nas amostras $\mathrm{BC} 03$ e $\mathrm{BC}$ 04, principalmente na BC 04 (11\% de albedo de maracujá) onde o sabor é mais evidenciado, concluindo que à medida que vai aumentando a concentração de albedo de maracujá, consequentemente, afeta a aceitação global por parte dos provadores.

Portanto, foi possível constatar como impressão global, que a maioria dos provadores tiveram uma boa aceitação das formulações desenvolvidas nos parâmetros analisados (cor, aroma, textura e sabor), em que gostaram extremamente e gostaram muito.

Foi avaliada também a intenção de compra dos provadores e foi observado que (Figura 7) 15\%, 40\% dos avaliadores afirmaram que "certamente comprariam" e "provavelmente comprariam" respectivamente o produto obtido a partir das formulações, $40 \%$ dos provadores afirmaram que "talvez comprariam", e apenas 3,3\% e 1,7\% afirmaram que "provavelmente não comprariam”, e “certamente não comprariam" respectivamente.

Figura 7 - Intenção de compra dos provadores para as barras de cereais.

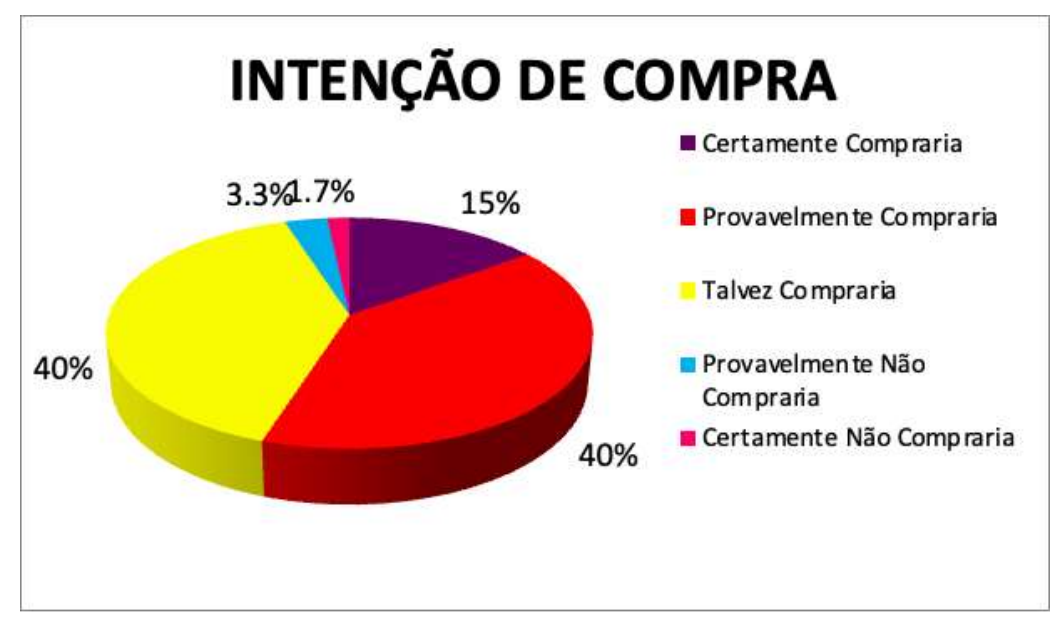

Fonte: Autores (2020).

Porém, vale ressaltar que o atributo "sabor" da formulação BC 04 (11\% de albedo de maracujá) foi o atributo que apresentou menor aceitação, por apresentar um sabor característico amargo. Entretanto, essa formulação apresentou maiores resultados de proteínas e fibras, e menores resultados de lipídios, carboidratos e valor calórico, se apresentado em termos nutricionais melhor do que as demais formulações e as barras produzidas comercialmente. 


\section{Considerações Finais}

A farinha de albedo de maracujá apresentou composição físico química satisfatória, destacando o alto teor de carboidratos complexos (fibra bruta) que pode apresentar potenciais benefícios a saúde sendo, portanto importante difundir o uso da farinha de albedo de maracujá além do uso da farinha integral da casca de maracujá para o desenvolvimento de produtos ricos em fibras ou até mesmo para a ingestão direta desse ingrediente rico em fibras, como alternativa ao aproveitamento dos resíduos da agroindústria.

Destaca-se também que o mercado local as farinhas de casca de maracujá tanto comerciais a granel e embaladas atendem os padrões exigidos pela legislação, porém apresenta alto teor de carboidratos simples em relação a farinha produzida no presente estudo. Desta forma conclui-se que as farinhas não tradicionais, como a de maracujá, seja do albedo ou da casca, podem ser utilizadas como ingrediente alternativo no desenvolvimento e enriquecimento de alimentos, favorecendo assim a redução dos resíduos da agroindústria e trazendo potenciais benefícios para saúde.

As análises realizadas nas barras de cereais forneceram resultados consistentes e mostraram que esta técnica é eficiente e interessante aumentando o valor agregado de tal subproduto. Neste trabalho observou-se que a substituição parcial da matéria-prima "aveia em flocos" (muito utilizada em processamento de barras de cereais), pela matéria-prima farinha de albedo de maracujá, mostrou-se um processo tecnológico viável para o reaproveitamento dos subprodutos do processamento de maracujás pelas indústrias de polpa. Pois as barras de cereais produzidas tiveram uma boa aceitação sensorial, onde a maioria dos provadores afirmaram que "gostaram extremamente" e "gostaram muito", afirmando que "certamente comprariam" e "provavelmente comprariam" o produto.

As barras de cereais elaboradas apresentaram valores mais elevados de proteínas e fibras quando comparada com as barras comerciais, trazendo benefícios à saúde. E apresentaram valores menores de lipídios e carboidratos, diminuindo assim o conteúdo calórico do alimento. Com relação às análises de cinzas e umidade foram constatados que as mesmas atendem aos padrões de aceitabilidade.

O presente estudo possibilitou conhecer as características das farinhas do maracujá e como esta pode ser empregada na elaboração ou enriquecimentos de alimentos, sendo necessário a realização de novos estudos a fim de verificar a aplicação em outros produtos, além de realização de pesquisas clínicas com seres humanos que busquem avaliar os impactos desses produtos à saúde, tendo em vista suas propriedades funcionais.

\section{Agradecimentos}

Os autores agradecem ao Instituto Federal de Educação, Ciência e Tecnologia do Ceará - Campus Sobral e Campus Limoeiro do Norte, à Fundação Cearense de Apoio ao Desenvolvimento Científico e Tecnológico (FUNCAP- BP4-017200154.01.00 / 20) e a Coordenação de Aperfeiçoamento de Pessoal de Nível Superior - CAPES.

\section{Referências}

Ambrosio-Ugri, M. C. B. \& Ramos, A. C. H. (2012). Elaboração de barra de cereais com substituição parcial de aveia por farinha da casca de maracujá. Revista Tecnológica. 1(21), 69-76.

Association of Official Analytical Chemists - AOAC (2000). Official methods of analysis of AOAC International (17 th ed.). Gaithersburg.

Baú, T. R., Cunha, M. A. A. d., Cella, S. M., Oliveira, A. L. J. d., \& Andrade, J. T. d. (2010). Barra alimentícia com elevado valor proteíco: formulação, caracterização e avaliação sensorial. Revista Brasileira de Tecnologia Agroindustrial, 4(1), 42 - 51. https://doi.org/10.3895/S1981-36862010000100005

Becker, T. d. S., \& Krüger, R. L. (2010, September). Elaboração de barras de cereais com ingredientes alternativos e regionais do Oeste do Paraná. Arquivos de Ciências da Saúde, 14(3), 217-224.

Bodart, M., Peñaranda, R. d., Deneyer, A., \& Flamant, G. (2008, October 3). Photometry and colorimetry characterisation of materials in daylighting evaluation tools. Building and Environment, 43, 2046-2058. 
Brasil. (2001a). Resolução - RDC n ${ }^{\circ}$ 40, de 21 de março de 2001. Regulamento técnico para rotulagem nutricional de alimentos e bebidas embaladas. Diário Oficial da União. Brasília, DF. Agência Nacional de Vigilância Sanitária - ANVISA

Brasil. (2001b). Resolução - RDC $n^{o}$ 12, de 02 de janeiro de 2001. Regulamento técnico sobre padrões microbiológicos para alimentos. Diário Oficial da União. Brasília, DF. Agência Nacional de Vigilância Sanitária - ANVISA.

Brasil. (2005). Resolução RDC $n^{\circ} 263$ de 22 de setembro de 2005. Diário Oficial da União, Brasília, DF. Agência Nacional de Vigilância Sanitária ANVISA. <http://portal.anvisa.gov.br/documents/33880/2568070/RDC_263_2005.pdf/d6f557da-7c1a-4bc1-bb84-fddf9cb846c3 >

Brito, I. P. de et al. (2004). Elaboração e avaliação global de barra de cereais caseira. Boletim do Centro de Pesquisa e Processamento de Alimentos, 22(1), 3550 .

Bueno R. O. G. (2005). Características de qualidade de biscoitos e barras de cereais ricos em fibra alimentar a partir de farinha de semente e polpa de nêspera. [Dissertação de Mestrado, Universidade Federal do Paraná, Curitiba].

Carvalho, M. G. de. (2008). Barras de cereais com amêndoas de chicha, sapucaia e castanha-do-gurgueia, complementadas com casca de abacaxi. [Dissertação de Mestrado, Universidade Federal do Ceará, Fortaleza, Ceará].

Catarino, R. P. F. (2016). Elaboração e caracterização de farinha de casca de maracujá para aplicação em biscoitos. [Trabalho de Conclusão de Curso, Universidade Tecnológica Federal do Paraná, Londrina - PR].

Cazarin, C. B. B.; Silva, J. L. da; Colomeu, T.C.; Zollner, R. de L. \& Maróstica Júnior (2014). Capacidade antioxidante e composição química da casca de maracujá (Passiflora edulis). Ciência Rural, 44 (9), 1699-1704. https://doi.org/http://dx.doi.org/10.1590/0103-8478cr20131437

Cichaczewski, A. (2012). Desenvolvimento de uma barra de cereal rica em fibras a partir do subproduto da extração do suco de maçã. 2012. [Trabalho de Conclusão de Curso, Universidade Tecnológica Federal do Paraná, Pato Branco]. http://repositorio.utfpr.edu.br:8080/jspui/bitstream/1/15439/2/PB_COQUI_2012_1_01.pdf.

Coelho, E. M.; Gomes, R. G.; Machado, B. A. S.; Oliveira, R. S.; Lima, M. dos S.; Azêvedo, L. C. \& Guez, M. A. U. (2017). Passion fruit peel flour e Technological properties and application in food products. Food Hydrocolloids 62, 158 - 164. https://doi.org/http://dx.doi.org/10.1016/j.foodhyd.2016.07.027

Coelho, K. D. (2006). Desenvolvimento e avaliação da aceitação de cereais matinais e barras de cereais à base de amaranto (Amaranthus cruentus L). [Dissertação de Mestrado, Nutrição Humana Aplicada, Universidade de São Paulo, São Paulo]. https://doi:10.11606/D.89.2006.tde-25102006-105736.

Corrêa, R. C.G.; Peralta, R. M.; Haminiuk, C. W. I.; Maciel, G. M.; Bracht, A. \& Ferreira, I. C. F. R. (2016). The past decade findings related with nutritional composition, bioactive molecules and biotechnological applications of Passiflora spp. (passion fruit). Trends in Food Science \& Technology, 58, 79-95. https://doi.org/http://dx.doi.org/10.1016/j.tifs.2016.10.006

Costa, E. L. d., Aguiar, E. V. d., Dominguez, M. L., Camargo, R., \& Stricker, T. (2015, December). Produção e aceitação de massa fresca tipo talharim enriquecida com farinha de maracujá (Passiflora edulis Sims f. flavicarpa) e verifcação do seu efeito na glicemia. Nutrire, 40(3), 352-360. https://doi.org/http://dx.doi.org/10.4322/2316-7874.71315

Costa, L. A. d., Bramorski, A., Teixeira, E., \& Amboni, R. D. d. M. C. (2005). Desenvolvimento de alimentos em barra à base de resíduos da fabricação de farinha de mandioca. Alimentos e Nutrição, 16(4), 389-396.

Damasceno, C. S. B., Silva, D. N., Damasceno, E. R., Oliveira, L. F. d., Porto, K. R. d. A., \& Candil, R. F. M. (2018, September). Effect of Passion fruit peel flour (Passiflora edulis) in bread acceptability. Visão Acadêmica, 19(3), 46-60.

Dutcosky, S. D., Grossmann, M. V. E., Silva, R. S. S., \& Welsch, A. K. (2006). Combined sensory optimization of a prebiotic cereal product using multicomponent mixture experiments. Food Chemistry, 98(4), 630-638. https://doi.org/doi:10.1016/j.foodchem.2005.06.029

Faveri, A.; Faveri, R. de; Broering, M. F.; Bousfield, I. T.; Goss, M. J.; Muller, S. P.; Pereira, R. O.; Silva, A. M. de O. e; Machado, I. D.; Quintão, N. L. M. \& Santin, J. R. (2020). Effects of passion fruit peel flour (Passiflora edulis f. flavicarpa O. Deg.) in cafeteria diet-induced metabolic disorders. Journal of Ethnopharmacology, 250.

Ferreira, M. S. L.; Santos, M. C. P.; Moro, T. M. A.; Basto, G. J.; Andrade, R. M. S. \& Gonçalves, E. C. B.A. (2015). Formulation and characterization of functional foods based on fruit and vegetable residue flour. Journal of Food Science and Technology, 52(2), 822-830. https://doi.org/10.1007/s13197-013$1061-4$

Francis, F. J.; Clydesdale, F. M. (1975). Food colorimetry: theory and applications, The Avi, Westport, Connecticut, USA.

Freitas, D. G. C. \& Moretti, R. H. (2006). Caracterização e avaliação sensorial de barra de cereais funcional de alto teor protéico e vitamínico. Ciência e Tecnologia de Alimentos, 26(2), 318-324. https://doi.org/10.1590/S0101-20612006000200014

Garcia, M.V.; Milani, M. S. \& Ries, E.F. (2019). Production optimization of passion fruit peel flour and its incorporation into dietary food. Food Science and Technology International, 26(2), 132-139. https://doi.org/10.1177/1082013219870011

Guimarães, M. M. (2007). Utilização de frutos de murici-passa no processamento e qualidade nutricional de barras de cereais. [Dissertação de Mestrado em Ciência e Tecnologia de Alimentos, Escola de Agronomia e Engenharia de Alimentos, Universidade Federal de Goiás, Goiânia - GO].

Gutkoski, L. C., Bonamigo, J. M. d. A., Teixeira, D. M. d. F., \& Pedó, I. (2007, June). Desenvolvimento de barras de cereais à base de aveia com alto teor de fibra alimentar. Ciências e Tecnologia de Alimentos, 27(2), 355-363.

Lafia, A. T., Gonçalves, L. S. C., \& Sousa, S. d. (2018, May 25). Obtenção da farinha do albedo de maracujá amarelo (Passiflora edulis sims), sua característica físico-química e sua microbiologia. I Conferência Nacional de Profissionais Licenciados em Ciências Agrarias/ Agrícolas / II Simpósio de Licenciatura em Ciências Agrarias, Bananeiras - PB. https://even3.blob.core.windows.net/anais/89367.pdf 
Lima, G. C. (2015). Farinha da casca de maracujá (Passiflora edulis): efeitos no tratamento e na prevenção da obesidade. [Tese de Doutorado, Universidade Estadual de Campinas, Faculdade de Engenharia de Alimentos, Campinas - SP]. http://repositorio.unicamp.br/jspui/handle/REPOSIP/321394

López-Vargas, J. H., Fernández-López, J., Pérez-Álvarez, J. A. \& Viuda-Martos, M. (2013). Chemical, physico-chemical, technological, antibacterial and antioxidant properties of dietary fiber powder obtained from yellow passion fruit (Passiflora edulis var. flavicarpa) co-products. Food Research International, 51, 756-763. http://dx.doi.org/10.1016/j.foodres.2013.01.055

Maia, S. M. P. C.; Pontes, D. F.; Garruti, D. dos S.; Oliveira, M. N. de; Arcanjo, R. S. S. \& Chinelate, G. C. B. (2018). Farinha de maracujá na elaboração de bolo de milho. Revista Verde de Agroecologia e Desenvolvimento Sustentável, 13(3), p. 328-336. http://dx.doi.org/10.18378/rvads.v13i3.5678

Marcelino, G.; Coleta, I. T.; Candido, C. J. \& Santos, E. F. dos. (2018). Caracterização e análise sensorial de cupcakes elaborados com diferentes concentrações de farinha de casca e polpa de baru (Dipteryx alata Vog.). Multitemas, 23(54), 265-281. http://dx.doi.org/10.20435/mulӨ.v23i54.1753

Marques, T. R. (2013). Aproveitamento tecnológico de resíduos de acerola: farinhas e barras de cereais. [Dissertação de Mestrado em Agroquímica, Universidade $\quad$ Federal de $\quad$ Lavras, Lavras $\quad-\quad$ MG] http://repositorio.ufla.br/jspui/bitstream/1/669/1/DISSERTA\%C3\%87\%C3\%83O_Aproveitamento\%20tecnol\%C3\%B3gico\%20de\%20res\%C3\%ADduos\%20 de $\% 20$ acerola $\% 20 \% 20$ farinhas $\% 20 \mathrm{e} \% 20$ barras $\% 20$ de $\% 20$ cereais.pdf

Matsuura, F. C. A. U. (2005). Estudo do albedo de maracujá e de seu aproveitamento em barras de cereais. [Tese Doutorado, Universidade Estadual de Campinas, Campinas - SP]. http://repositorio.unicamp.br/handle/REPOSIP/254407

Mokrzycki, W.S.; Tatol, M. (2011). Colour difference Se - a survey. Machine graphics \& Vision International Journal. 20(4), 383-411.

Moraes, A. M. d., \& Fonseca, J. J. S. d. (2017). Metodologia da Pesquisa Científica (1st ed.). Faculdade INTA.

Morais, E. C. de; Patias, S. G. O.; Costa, E. S.; Sandri, D. de O.; Picanço, N. F. M. \& Faria, R. A. P. G. de. (2018). Brazilian Journal of Food Research, 9(2), $1-14$

Nascimento, E. M. da G. C. do.; Ascheri, J. L. R.; Carvalho, C. W. P. de. \& Galdeano, M. C. (2013). Benefícios e perigos do aproveitamento da casca de maracujá (Passiflora edulis) como ingrediente na produção de alimentos. Revista Instituto Adolfo Lutz, 72(1), 1-9.

Oliveira, E. M. S. (2009). Caracterização de rendimento das sementes e do albedo do maracujá para aproveitamento industrial e obtenção da farinha da casca e pectina. [Dissertação de Mestrado em Produção Vegetal, Centro de Ciências e Tecnologias Agropecuárias, Campos dos Goytacazes - RJ: UENF].

Padilha, T. \& BASSO, C. (2015). Biscoitos com resíduo de manga, maracujá e jabuticaba. Disciplinarum Scientia, Série: Ciências da Saúde, $16(1), 79$ - 88.

Pereira, A. S., Shitsuka, D. M., Parreira, F. J., \& Shitsuka, R. (2018). Metodologia da pesquisa científica (1st ed.). UAB/NTE/UFSM. https://repositorio.ufsm.br/bitstream/handle/1/15824/Lic_Computacao_Metodologia-Pesquisa-Cientifica.pdf?sequence=1

Reis, L. C. R. (2018). Composição físico-química e de compostos bioativos de diferentes espécies de maracujá, estabilidade do suco e aproveitamento da farinha da casca de maracujá laranja. [Tese de Doutorado, Universidade Federal do Rio Grande do Sul, Instituto de Ciência e Tecnologia de Alimentos, Programa de Pós-graduação em Ciências e Tecnologia de Alimentos, Porto Alegre - RS].

Reolon, C. A. (2008). Fatores de influência nas características físico-químicas e minerais da casca do maracujá e seu aproveitamento na elaboração de doce. [Dissertação Mestrado em Agronomia, Universidade Estadual do Oeste do Paraná, Marechal Cândido Rondon].

Ribeiro, S. A. L.; Cavalcanti, M. A. Q.; Fernandes, A. J. S. \& Lima, D. M. M. (2003). Fungos filamentosos isolados de produtos derivados do milho comercializados em Recife, Pernambuco. Revista Brasileira de Botânica, 26(2), 223-229. https://doi.org/10.1590/S0100-84042003000200010

Sampaio, C. R. P. et al. (2004). Verificação da informação nutricional em rotulagem quanto à designação "light" de cereais em barra: uma pesquisa de mercado. In: Congresso Brasileiro de Nutrição (CONBRAN) - Nutrição e Qualidade de Vida: enfrentando desafios. Campo Grande.

Sarantápoulos, C.I. G. L; De Oliveira., L. M.; Canavesi, É. (2001). Requisitos de conservação de alimentos em embalagens flexíveis. Campinas: CETEA / ITAL.

Silva, D.; Pagani, A. \& Souza, R. (2018). Elaboração de cupcake adicionado de farinha de resíduo de umbu cajá: características sensoriais e químicas. Revista Ciência (In) Cena. On-line, 1(7), 28-46.

Silva, E. C. O. d. (2017). Influência do flavedo e da maceração nas características físico-químicas da farinha da casca de maracujá. [Dissertação de Mestrado, Universidade Federal de Campina Grande. Campina Grande, Paraíba - PB].

http://dspace.sti.ufcg.edu.br:8080/jspui/bitstream/riufcg/613/1/ELAINE\%20CRISTINA\%20OLIVEIRA\%20DA\%20SILVA\%20\%e2\%80\%93\%20DISSERTA $\%$ c3\%87\%c3\%830\%20\%28PPGEG\%29\%202017.pdf

Silva, E. C. O. da.; Silva, A, W. P. da.; Silva, A, E. T. da.; Lopes, J. D. \& Gusmão, O, R. P. de. (2016). Obtenção e caracterização da farinha do albedo de maracujá (Passiflora edulis f. flavicarpa) para uso alimentício. Revista Verde de Agroecologia e Desenvolvimento Sustentável, 11(3), 69-74.

Silva, I. Q.; Oliveira, B. C. F. de; Lopes, A. S. \& Pena, R. da S. (2009). Obtenção de barra de cereais adicionada do resíduo industrial de maracujá. Alimentos e Nutrição, 20(2). 321-329.

Silva, D. J. \& Queiroz, A.C. (2002). Análise de alimentos: métodos químicos e biológicos. Viçosa, UFV.

Silveira, P. T. S. et al. (2014). Barra de cereal com farinha da casca da berinjela (solanum melongena, 1.): análise microbiológica, caracterização química e aceitação sensorial. 26, III CBPFH. Cruz das Almas - BA.

Spinosa, E. de A. (2017). Caracterização de farinha da casca de maracujá amarelo e maracujá-do-cerrado. Revista Científica Semana Acadêmica, MMXVII (000100). https://semanaacademica.com.br/artigo/caracterizacao-de-farinha-da-casca-de-maracuja-amarelo-e-maracuja-do-cerrado 
Research, Society and Development, v. 10, n. 9, e60010918415, 2021

(CC BY 4.0) | ISSN 2525-3409 | DOI: http://dx.doi.org/10.33448/rsd-v10i9.18415

Torres, E. R. (2009). Desenvolvimento de barras de cereais formuladas com ingredientes regionais. [Dissertação de Mestrado em Engenharia de Processos, Universidade Tiradentes, Aracaju - SE]. https://mestrados.unit.br/pep/wp-content/uploads/sites/4/2016/04/DESENVOLVIMENTO-DE-BARRA-DECEREAIS-FORMULADAS-COM-INGREDIENTES-REGIONAIS.pdf 